\title{
Novel preparation of low-cost support for NaA zeolite membrane by utilizing natural clay
}

\author{
Gangling Chen ${ }^{1} \cdot$ Jianying Zhang ${ }^{1} \cdot$ Tianlin $\mathrm{Ma}^{1} \cdot$ Yujie Wang $^{1} \cdot$ Guihua Chen ${ }^{3} \cdot$ Youzhi Guo $^{2}$
}

Received: 6 July 2021 / Accepted: 31 August 2021 / Published online: 12 September 2021

(c) The Author(s) 2021

\begin{abstract}
The membrane support is the basis for the preparation and application of the zeolite membrane and its cost and properties directly determine the performance of the zeolite membrane as well as its industrial applications. In this paper, the direct synthesis of NaA zeolite membrane on a novel low-cost support via an in situ reaction by utilizing natural clay can enable a significant reduction in manufacturing costs. During the preparation of the support for the NaA zeolite membrane, additives, such as $\mathrm{Al}_{2} \mathrm{O}_{3}, \mathrm{Al}(\mathrm{OH})_{3}$ and $\mathrm{AlF}_{3}$, were combined with kaolin clay and used as alumina precursors. Using the resulting porous mullite support, the effects of the firing temperature on the permeability and pore structure of the support were investigated extensively. The results of the experiment showed that silica in the natural clay was reacted by the $\mathrm{Al}_{2} \mathrm{O}_{3}$ precursor additives, producing a needle-like mullite in situ that served as a rigid skeleton porous structure for the support. Thus, a network porous structure of the mullite support could be formed during sintering process. The prepared network porous structure mullite supports exhibited a high pure water permeance of $3324 \mathrm{~L} \mathrm{~m}^{2} \mathrm{~h}^{1} \mathrm{bar}^{1}$, open porosity of $41.8 \%$ and a mean pore size of $1.36 \mu \mathrm{m}$ which was ideal for the preparation of the NaA zeolite membrane.
\end{abstract}

Keywords Natural clay $\cdot$ Low-cost $\cdot$ Zeolite membrane

\section{Introduction}

The development of new and efficient membrane separation technologies is especially useful for overcoming issues with traditional transformation processes, including increasing energy efficiency in industrial operations and minimizing unnecessary pollution in the environment (Wang et al. 2019; Park et al. 2017; Gao et al. 2021; Zhu et al. 2021). Zeolite has been demonstrated to be useful as a membrane material because of its unique advantages that are specific to component separation and reaction for this research and development of membrane technology. Therefore, the development of zeolite-based materials have been popular in the inorganic

Youzhi Guo

gyz57123@126.com

1 School of Material Science and Chemical Engineering, Chuzhou University, Chuzhou 239000, China

2 The Seawater Desalination and Utilization of the Alternative Water Resources Research Center of Hohai University, Hohai University, Nanjing 210009, China

3 School of Pharmaceutical and Material Engineering, Taizhou University, Jiaojiang 318000, China membrane materials field of research (Lai et al. 2003; Chen et al. 2020; Liang et al. 2021, 2017; Dan et al. 2015). However, the increased production of zeolite membranes has been complicated by its complex synthesis, demand for scarce raw materials, and requirements for supports, which makes the cost of production higher and ultimately limits its application in membrane technologies. Because of these factors, this technology has not yet been widely adopted. The membrane support is the basis for the preparation and application of the zeolite membrane and its preparation cost is about $2 / 3$ of the membrane cost, so the preparation and properties of supports directly determine the performance of the zeolite membrane as well as its industrial applications to a certain extent (Kazemimoghadam and Mohammadi 2006; $\mathrm{Li}$ et al. 2013, 2016). Therefore, there is an unmet need to find or develop cheap synthetic raw materials that can be used in the preparation of support membrane materials that can not only demonstrate excellent separation performance but also are compatible with both the methods for synthesizing zeolite membranes and its applications.

Mullite $\left(3 \mathrm{Al}_{2} \mathrm{O}_{3} \cdot 2 \mathrm{SiO}_{2}\right)$ exhibits excellent corrosion resistance, has a high thermal shock, and requires a relatively low sintering temperature during preparation. Moreover, the 
elemental composition of mullite is similar to the elemental composition of the NaA zeolite. Therefore, the use of mullite as a support material for zeolite membranes would greatly reduce the introduction of different ions during membrane synthesis, thereby maintaining the properties of the $\mathrm{NaA}$ zeolite membrane during synthesis (Li et al. 2013; Louisa Tak Yin and Chau 2001). Although the preparation of high purity porous mullite ceramics is generally conducted using a wet chemical method, such as the gel-sol method, methods such as hydrothermal synthesis, co-precipitation, or chemical vapor deposition can also be used, but the production costs of porous mullite ceramics using these methods are higher because their complex preparation process and production capacities (Huang et al. 2013; Shao et al. 2014). These costs can be greatly reduced by utilizing natural clay (e.g., kaolin) as a raw material in the preparation of porous mullite ceramics (Kazemimoghadam and Mohammadi 2006; $\mathrm{Li}$ et al. 2016). However, since the $\mathrm{SiO}_{2}$ content in clay minerals is typically higher than in mullite, the additional $\mathrm{SiO}_{2}$ will produce impurities within the clay, leading to the formation of considerable amounts of glassy phase that will cause densification of the body (Fig. 1b). This process limits the use of clay materials for the preparation of porous mullite supports for zeolite membranes because the presence of large numbers of glassy phases in the product will affect the product's overall separation performance.

Instead, the addition of $\mathrm{Al}_{2} \mathrm{O}_{3}$ into the clay raw materials is capable of reducing the extent of glassy phase formation

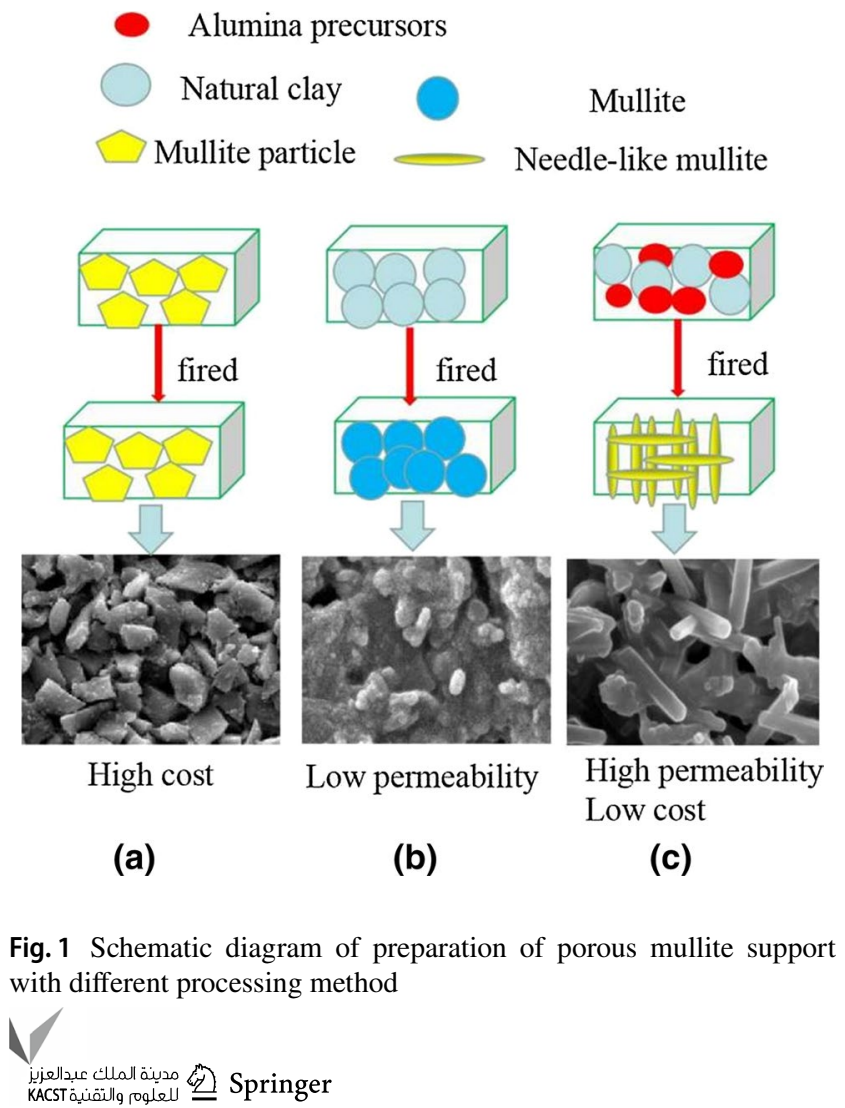

in $\mathrm{SiO}_{2}$, increasing the mullite with a higher amount. Herein, a new processing method was directly applied in the preparation of a porous mullite support for the NaA zeolite membrane using additional suitable alumina precursors. The excess silica in the natural clay was expected to be reacted by the $\mathrm{Al}_{2} \mathrm{O}_{3}$ precursor additives, producing a needle-like mullite in situ that served as a rigid skeleton porous structure for the support. Thus, a network porous structure of the mullite support could be formed during sintering process (Fig. 1c). Subsequently, the effects of the temperature during the sintering process of the mullite support on the porosity, Pure water flux (PWF), pore size, and penetrating porosity of the mullite were extensively investigated.

\section{Experimental}

\section{Preparation of support for $\mathrm{NaA}$ zeolite membranes}

Kaolin $\left(\mathrm{Al}_{2} \mathrm{O}_{3} \cdot 2 \mathrm{SiO}_{2}\right.$, China Kaolin Clay Co., Ltd) was the main raw material of the precursors. alumina, hydrafil, and aluminum fluoride were added to the kaolin as the sources of aluminum. The elemental compositions of the starting materials were determined by the Switzerland ARL 9800 XP $\mathrm{X}$-ray fluorescence spectrometer. First, the mullite precursor powder with $70 \mathrm{wt} \% \mathrm{Al}_{2} \mathrm{O}_{3}$ was prepared by combining kaolin and aluminum source. The aluminum source consists of $85 \mathrm{wt} \% \mathrm{Al}(\mathrm{OH})_{3}$ and $15 \mathrm{wt} \% \alpha-\mathrm{Al}_{2} \mathrm{O}_{3}$. The mullite precursor powder was doped with $5 \mathrm{wt} \% \mathrm{AlF}_{3}$. Furthermore, the mullite precursor powder was ball milled for $12 \mathrm{~h}$ to combine them. Some lubricant and a few binders were also added into the mixed mullite precursor, which were shaped into cylinders $(\Phi 25 \mathrm{~mm} \times 3 \mathrm{~mm})$ green bodies under an axial pressure of $8 \mathrm{MPa}$. Finally, the samples were sintered in an air atmosphere from $1300-1550{ }^{\circ} \mathrm{C}$ for $2 \mathrm{~h}$ and cooled gradually to room temperature.

\section{Characterization of support}

The microstructure of the support was characterized with a scanning electron microscope (S-4800 Hitachi, Japan). The crystal phases of membranes were analyzed with an X-ray diffractometer (XRD, MiniFlex 600, Rigaku, Japan). The Archimedes method (GB1996-80) was employed for determining the open porosity of the samples using Deionized (DI) water as the medium. The membrane pore size was analyzed with the nitrogen bubbling method using a pore size analyzer. The permeability performances of the samples were also determined in DI water as the medium using the filtration device shown in Fig. 2. The operating pressure of the filtration device was maintained within a range of 0.1-0.3 MPa. Three different data sets were acquired, one 


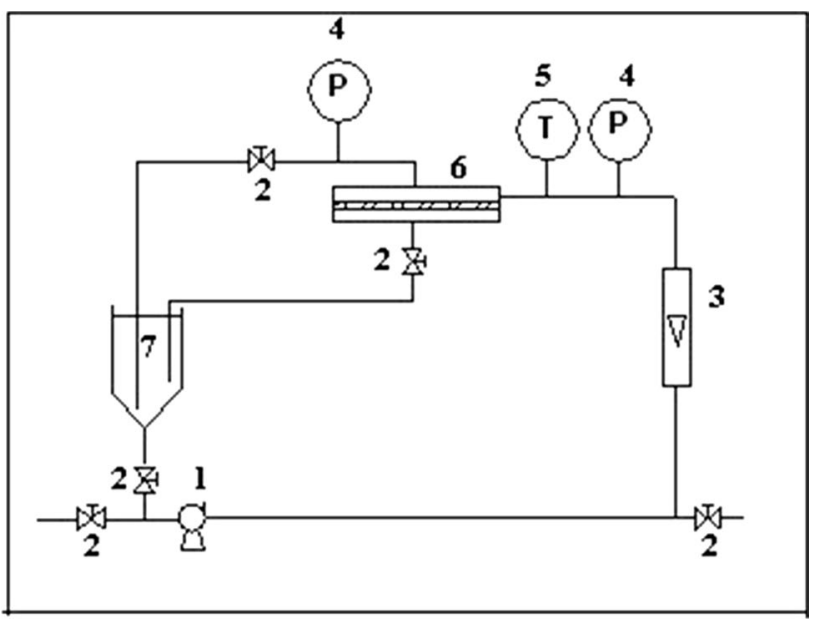

Fig. 2 Schematic diagram of filtration experimental equipment: 1-centrifugal pump; 2- needle valve; 3 - flow meter; 4- pressure gage; 5- temperature meter; 6- plate membrane module; 7- stock tank

for each of the operating pressures, and the average flow rate was determined based on the corresponding pressure.

The penetrating porosity $(\varepsilon)$ depends on the water flow and average pore size of the membrane ( $r$ ) and is calculated via Eq. (1) (Lukasiewicz and Reed 1988; Reed 1993):

$\varepsilon=24\left(\frac{d Q}{d P}\right) \frac{\eta L}{A r^{2}}$

where $\frac{d Q}{d P}$ is the slope of the curve of generated from the plot of the average flow rate and corresponding operating pressure, $\eta$ is the viscosity of the liquid, and the area and the thickness of the membrane are represented $\mathrm{A}$ and $\mathrm{L}$, respectively.

\section{Results and discussion}

\section{Microstructure analysis of the samples}

The SEM images of the prepared sample shown in Fig. 3. Clearly show that the samples sintered at a temperature of $1500{ }^{\circ} \mathrm{C}$ had high porosity and a network porous structure. The pore structure of the sample, which was mostly composed of needle-like grains. Each needle-like crystal had an average length of, approximately $3 \mu \mathrm{m}$. Mohamed et al. (1990) observed a similar morphology. EDX conducted on various sections of the needle-like crystal found that the mass fractions of $\mathrm{Al}_{2} \mathrm{O}_{3}$ and $\mathrm{SiO}_{2}$ were $72.2 \%$ and $27.8 \%$, respectively, which were in agreement with the composition of the mullite. The results from the XRD spectra in Fig. 4. Confirmed that the generated needle-like crystals were composed of mullite.

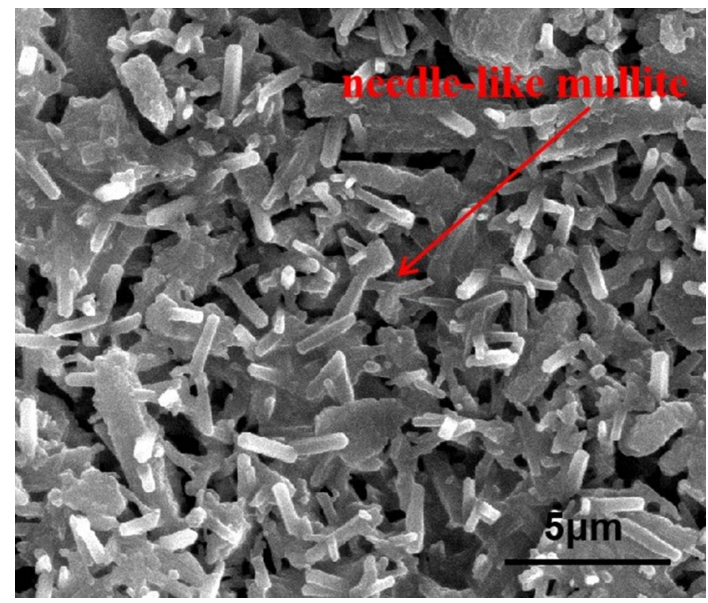

Fig. 3 SEM image of the sample which was sintered at a temperature of $1500{ }^{\circ} \mathrm{C}$ for $2 \mathrm{~h}$

It is well-known that the $\mathrm{SiO}_{2}$ content in clay minerals is higher than the $\mathrm{SiO}_{2}$ content in mullite. When the samples were sintered, the excess $\mathrm{SiO}_{2}$ in the natural clay was reacted by the $\mathrm{Al}_{2} \mathrm{O}_{3}$ precursor additives, producing a needle-like mullite in situ that served as a rigid skeleton porous structure for the support. Thus, a network porous structure of the mullite support could be formed during sintering process. The network porous structure membrane material might have a high permeability.

\section{Phase composition of the supports}

Figure 4 shows the XRD pattern of the support sintered at a temperature of $1500{ }^{\circ} \mathrm{C}$ for $2 \mathrm{~h}$, indicating that most of the strong diffraction peaks that were present in the spectra were

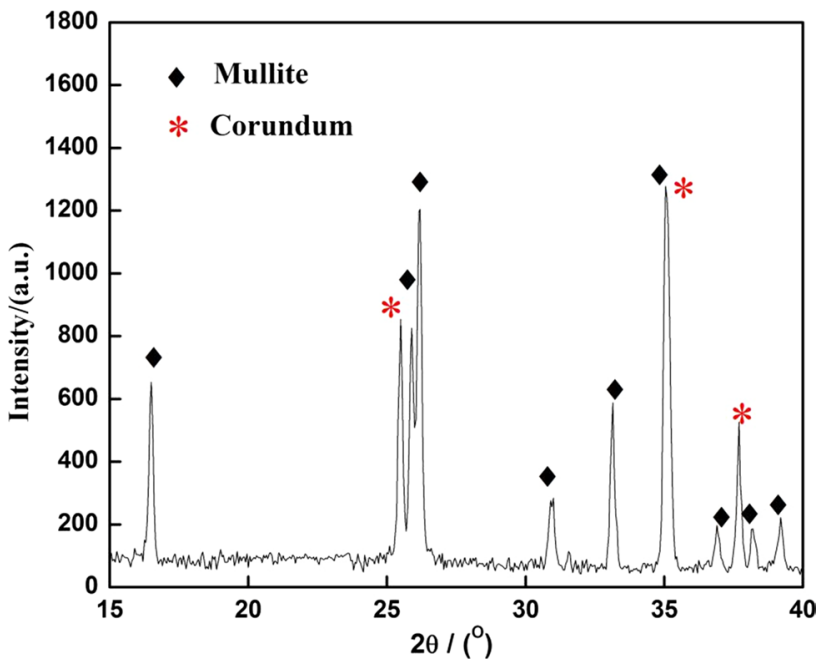

Fig. 4 X-ray diffraction pattern of the support sintered at $1500{ }^{\circ} \mathrm{C}$ for $2 \mathrm{~h}$ 
the mullite phase. Some weaker corundum diffraction peaks were present in the spectra too. These results show that the support is mainly composed of mullite and a small amount of corundum. The mullite mainly come from the primary mullite generated by high-temperature decomposition of natural clay and secondary mullite formed by in situ reaction of excess silicon oxide in natural clay with added aluminum precursor. During the high-temperature sintering process, the $\mathrm{Al}_{2} \mathrm{O}_{3}$ precursor additives reacted with the excess silica in the natural clay and the mullite formed in situ, which decreased the amount of glass phase generated by hightemperature decomposition of natural clay and prevent the formation of high-temperature liquid phase of silica, which is helpful to prepare the porous mullite membrane.

\section{Pore structure of the supports}

\section{Average pore sizes}

Figure 5 shows the dependence of the mean pore size of the supports on the sintering temperature, indicating that the mean pore size of the supports increased as the sintering temperature increased, with pore sizes of $0.81-1.5 \mu \mathrm{m}$ resulting from temperatures of $1400-1550{ }^{\circ} \mathrm{C}$. Larger the mean pore size of the supports was manifested by sintering at higher temperatures. The main reason is that the excess $\mathrm{SiO}_{2}$ from the natural clay underwent an in situ reaction and formed the skeletal structure of needle-like mullite during the high-temperature sintering process. More and more $\mathrm{SiO}_{2}$ was consumed with the $\mathrm{Al}_{2} \mathrm{O}_{3}$ precursor additives while the mullite's stiff skeletal structure became more pronounced after in situ formation with the sintering temperature increasing. The production and growths of the skeletal structure of mullite crystal was beneficial for increasing the

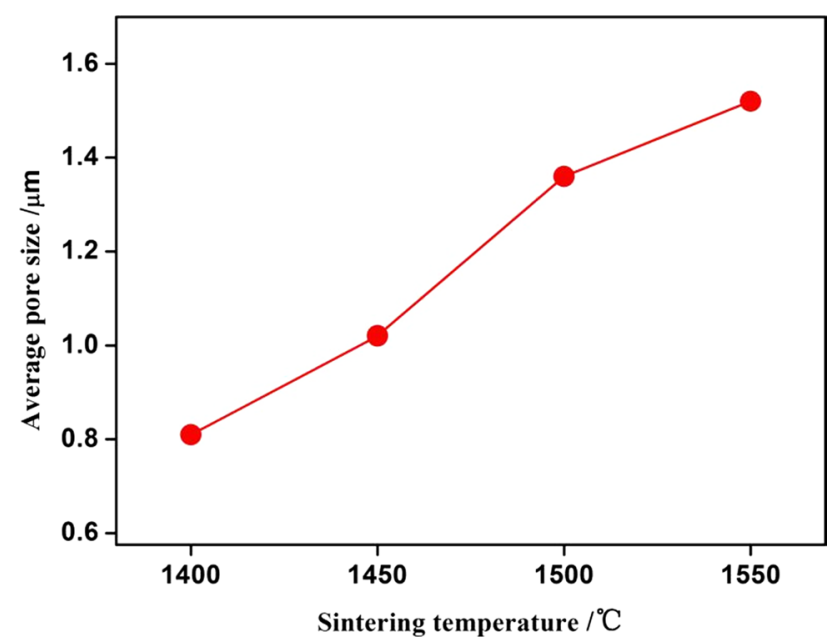

Fig. 5 Effect of the sintering temperature on the mean pore size of supports sintered at different temperatures $\left(1400-1550{ }^{\circ} \mathrm{C}\right)$ size of the pore, resulting in an increased average pore size, which helped to manifest an excellent pore structure.

\section{Porosity}

Figure 6 presents the effect of the sintering temperature on the porosity of supports. As shown in Fig. 6, the increase in sintering temperature always lead to a decrease in the porosity of supports. Nonetheless, the support still exhibited high porosity above $36 \%$. The increase in the sintering temperature promotes the densification process, which causes the ceramic grains to grow and the pores between the grains gradually to shrink. On the other hand, the additive $\mathrm{Al}(\mathrm{OH})_{3}$ experiences a $60 \%$ volume contraction during decomposition (Deng et al. 2001). The pores left by the $\mathrm{Al}(\mathrm{OH})_{3}$ after decomposition inhibit the process of densification, because the distance between ceramic particles becomes farther so that more energy is required to diffuse to the position where sintering can occur. At the same time, the excess $\mathrm{SiO}_{2}$ from the natural clay underwent an in situ reaction and formed the skeletal structure of needle-like mullite during the high-temperature sintering process, which provided a high porosity.

\section{Permeability of sintered supports}

Figure 7 presents the variation of pure water flux with applied pressures $(0.1-0.3 \mathrm{MPa})$ for the supports sintered at different temperatures $\left(1400{ }^{\circ} \mathrm{C}-1500{ }^{\circ} \mathrm{C}\right)$. It can be seen that the water flux linearly increases with an increase in pressure which is due to the fact that the pressure is a driving force. Additionally, it also appears that the support sintered at $1500{ }^{\circ} \mathrm{C}$ has a higher pure water flux than the other supports sintered at other temperatures under the same operating pressures. At an operating pressure of

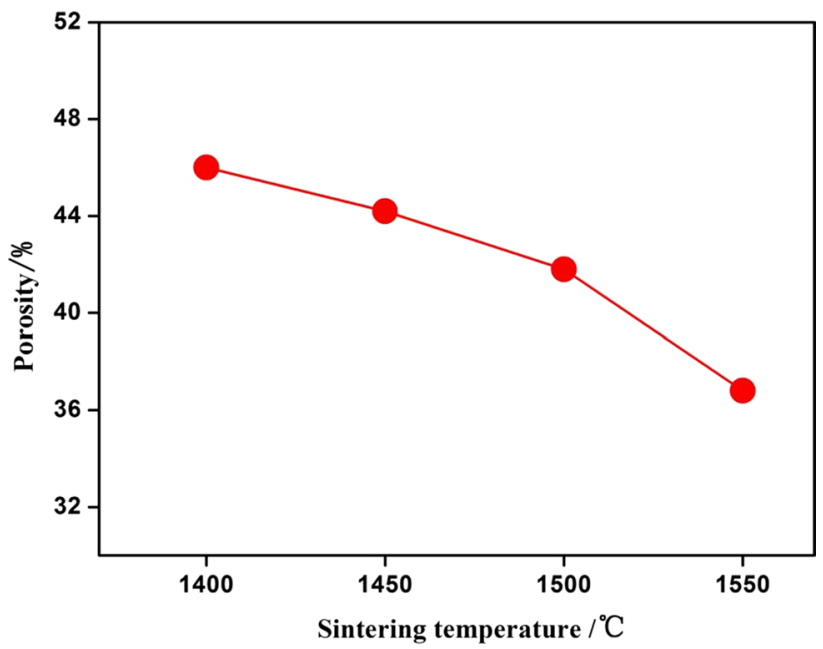

Fig. 6 Effect of sintering temperature on porosity of supports sintered at different temperatures $\left(1400-1550{ }^{\circ} \mathrm{C}\right)$ 


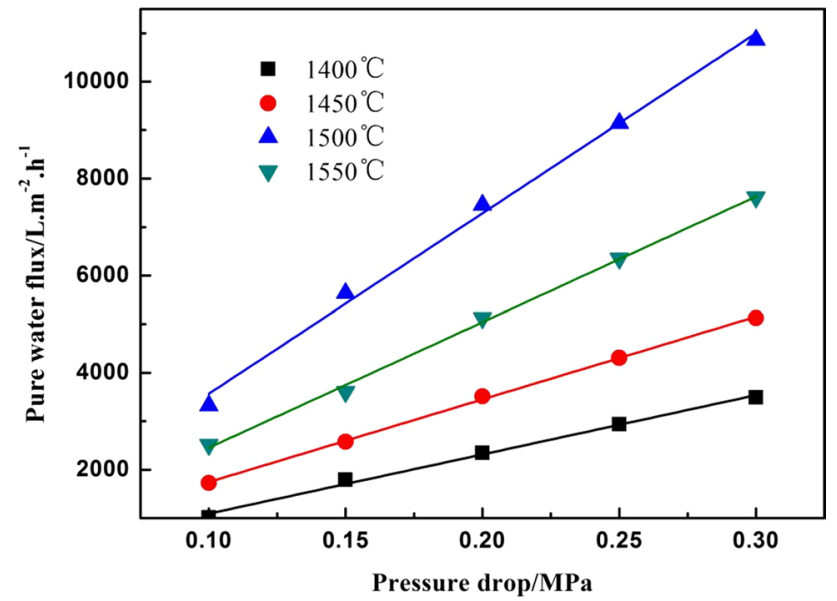

Fig. 7 Variation of pure water flux with applied pressures (0.1$0.3 \mathrm{MPa})$ for the supports sintered at different temperatures $\left(1400{ }^{\circ} \mathrm{C}-1500{ }^{\circ} \mathrm{C}\right)$

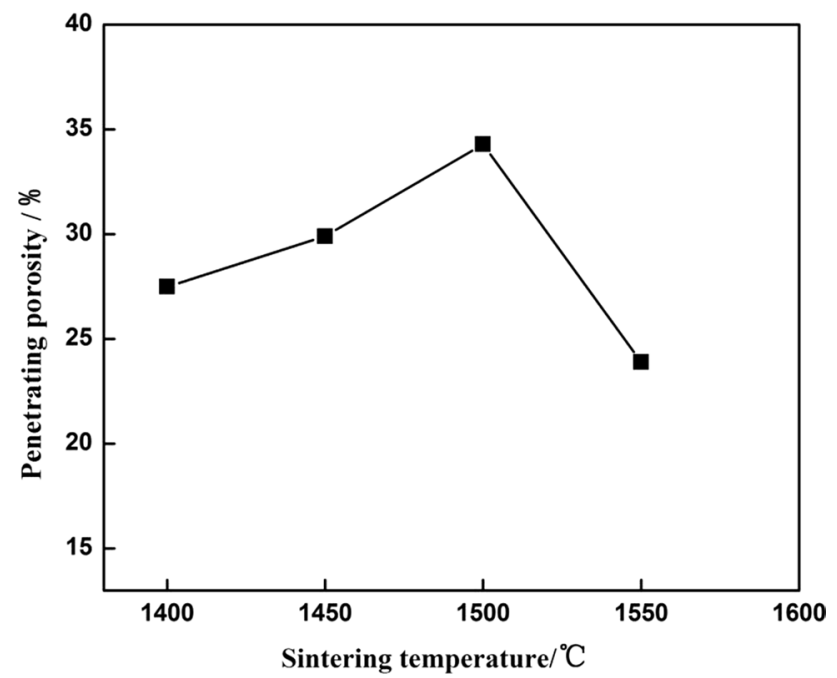

Fig. 8 Effect of sintering temperature on penetrating porosity of supports sintered at different temperatures $\left(1400-1550^{\circ} \mathrm{C}\right)$

$0.1 \mathrm{MPa}$, the flow rate of the pure water through the support sintered at $1500{ }^{\circ} \mathrm{C}$ was $3324 \mathrm{~L} \cdot \mathrm{m}^{-2} \cdot \mathrm{h}^{-1}$. These results were attributed to the dependence of the flow characteristics on the porosity and the pore size (Colombo et al. 2008). The measurement of penetrating porosity of the supports as a function of sintering temperature is depicted in Fig. 8. The pores in supports consisted of penetrating and non-penetrating pores. The pure water permeance of the supports was affected by the pore size and penetrating porosity. As shown in Fig. 8, the maximum penetrating porosity was up to $34.3 \%$ for the support sintered at $1500{ }^{\circ} \mathrm{C}$, which was up to $82 \%$ of the total porosity. The high membrane penetrating porosity contributed to the low fluid resistance and high water permeability.

\section{Membranes preparation}

The NaA zeolite membranes were prepared using the sample sintered at $1500{ }^{\circ} \mathrm{C}$ as supports. The membrane gel had a mole composition of $1 \mathrm{Al}_{2} \mathrm{O}_{3}: 2 \mathrm{SiO}_{2}: 2 \mathrm{Na}_{2} \mathrm{O}: 120 \mathrm{H}_{2} \mathrm{O}$. The microstructure and morphology of the synthesized zeolite membrane were observed by scanning electron microscopy (SEM, S-4800II, Hitachi). The synthesized membranes were analyzed by X-ray diffraction (Bruker, D8-Advance, Germany). Based on the SEM micrograph shown in Fig. 9, the zeolite NaA membrane developed in the sample sintered at $1500{ }^{\circ} \mathrm{C}$. The upper surface of synthesized membrane showed that the sample was fully covered with aggregated grains of the NaA zeolite crystals. The entire structure of the synthesized membrane is shown in the sectional SEM image in Fig. 9b. In addition, based on the XRD spectra of the zeolite NaA membrane that formed on the sample sintered at $1500{ }^{\circ} \mathrm{C}$ (Fig. 10), the phases in the synthesized membrane were consistent with $\mathrm{NaA}$ zeolite. Furthermore, the XRD analysis confirmed that the membrane formed was NaA membrane. As application to evaluate separation performance of the membrane, the NaA zeolite membrane was used for dehydration of ethanol aqueous solutions using pervaporation experiment with water content $10 \mathrm{wt} \%$ at temperature of $70{ }^{\circ} \mathrm{C}$. Experimental results showed that the separation factor and the permeate flux of the membrane were 11,100 and $3.1 \mathrm{~kg} \cdot \mathrm{m}^{-2} \cdot \mathrm{h}^{-1}$, respectively, which showed that separation performance of the membrane is good. The experimental results indicated that the support that was sintered at $1500{ }^{\circ} \mathrm{C}$ was suitable for the synthesis of $\mathrm{NaA}$ zeolite membrane.

\section{Conclusions}

The direct synthesis of $\mathrm{NaA}$ zeolite membranes on a novel low-cost support structure via an in situ reaction by utilizing natural clay can enable a significant reduction in manufacturing costs. During the preparation of the support for the $\mathrm{NaA}$ zeolite membrane, additives, such as $\mathrm{Al}_{2} \mathrm{O}_{3}, \mathrm{Al}(\mathrm{OH})_{3}$, and $\mathrm{AlF}_{3}$, were combined with the minerals in kaolin clay and used as alumina precursors. The excess $\mathrm{SiO}_{2}$ in the natural clay was consumed by the $\mathrm{Al}_{2} \mathrm{O}_{3}$ precursor additives, producing a needle-like mullite in situ that served as a rigid skeleton structure for the porous support, the network structure of the support indicated good permeability. Furthermore, upon optimization, the prepared network porous structure mullite supports exhibited a high pure water permeance of $3324 \mathrm{~L} \cdot \mathrm{m}^{-2} \cdot \mathrm{h}^{-1} \cdot \mathrm{bar}^{-1}$, open porosity of $41.8 \%$ and an mean pore size of $1.36 \mu \mathrm{m}$, which was ideal for the preparation of the NaA zeolite membrane. 

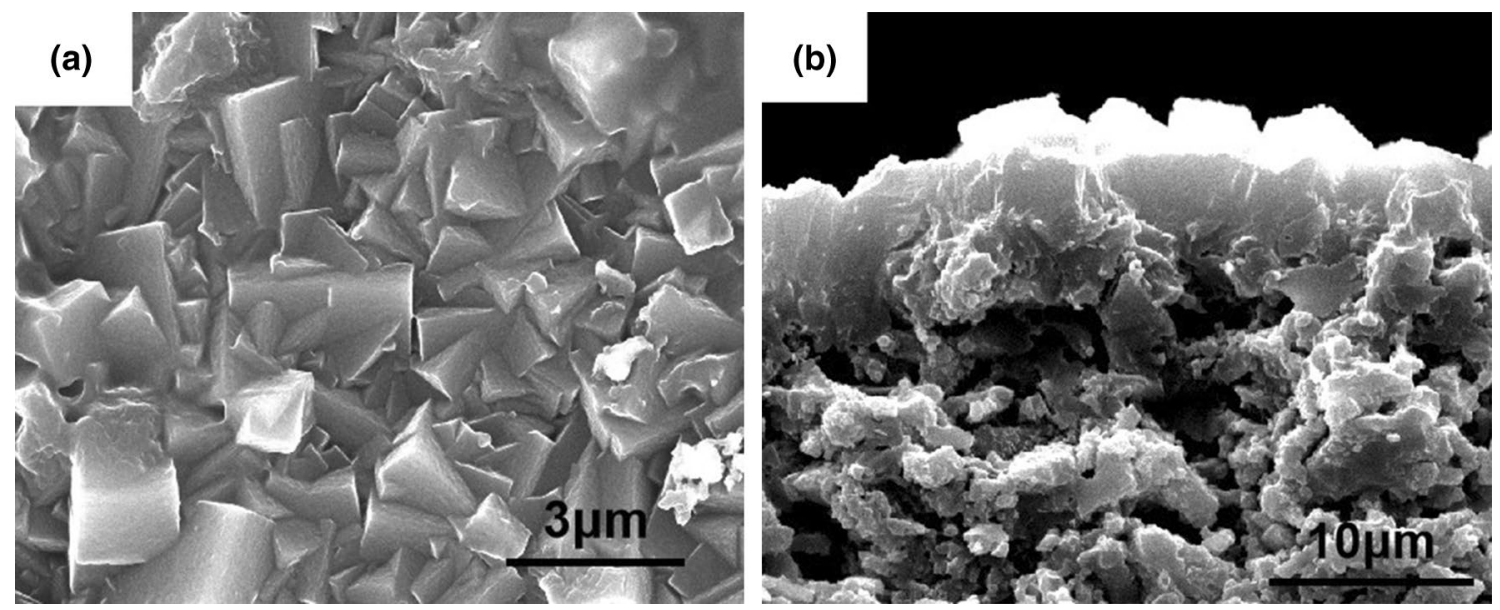

Fig. 9 SEM photos of surface (a) and cross section (b) of zeolite NaA membrane that formed on the sample sintered at temperatures of $1500{ }^{\circ} \mathrm{C}$

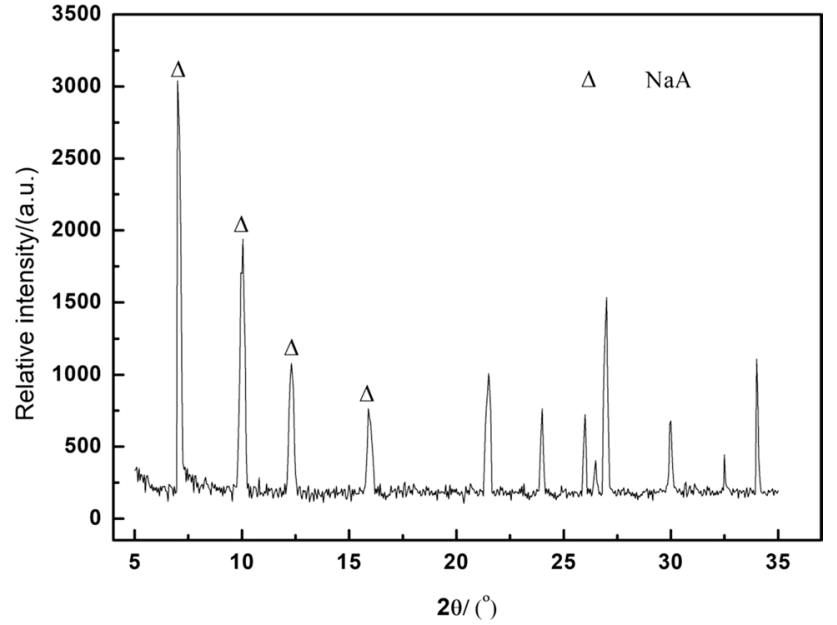

Fig. $10 \mathrm{XRD}$ of zeolite NaA membrane that formed on the sample sintered at temperatures of $1500{ }^{\circ} \mathrm{C}$

Acknowledgements This work was supported by the University Natural Science Research Key Project of Anhui Province (KJ2019ZD043), Anhui Provincial Natural Science Foundation of China(1808085MB50), Zhejiang Provincial Natural Science Foundation of China (LY19E020002).

\section{Declarations}

Conflict of interest All authors certify that they have no affiliations with or involvement in any organization or entity with any financial interest or non-financial interest in the subject matter or materials discussed in this paper.

Ethical approval This article does not contain any studies with human participants or animals performed by any of the authors.
Open Access This article is licensed under a Creative Commons Attribution 4.0 International License, which permits use, sharing, adaptation, distribution and reproduction in any medium or format, as long as you give appropriate credit to the original author(s) and the source, provide a link to the Creative Commons licence, and indicate if changes were made. The images or other third party material in this article are included in the article's Creative Commons licence, unless indicated otherwise in a credit line to the material. If material is not included in the article's Creative Commons licence and your intended use is not permitted by statutory regulation or exceeds the permitted use, you will need to obtain permission directly from the copyright holder. To view a copy of this licence, visit http://creativecommons.org/licenses/by/4.0/.

\section{References}

Caro J, Noack M, Kolsch P, Schafer R (2000) Zeolite membranes-state of their development and perspective. Microporous Mesoporous Mater 38:3-24

Chen F, Li Y, Huang A (2020) Hydrophilicity reversal by post-modification: hydrophobic zeolite FAU and LTA coatings on stainlesssteel-net for oil/water separation. Colloids Surf A: Physicochemical Eng Aspects. https://doi.org/10.1016/j.colsurfa.2020.124936

Cho CH, Oh KY, Yeo JG, Si KK, Lee YM (2010) Synthesis, ethanol dehydration and thermal stability of NaA zeolite/alumina composite membranes with narrow non-zeolitic pores and thin intermediate layer. J Membr Sci 364:138-148

Colombo P (2008) In Praise of Pores, sci 22:381-383

Dan G, Tong M, Yuli C, Shengui J (2015) Effect of alkali on desulfurization efficiency of ZSM-5 zeolite membrane. Chem Technol Fuels Oils 51:345-352

Deng ZY, Fukasawa T, Ando M (2001) Microstructure and mechanical properties of porous alumina ceramics fabricated by the decomposition of aluminum hydroxide. J Am Ceram Soc 84:2638-2644

Gao X, Da C, Chen C, Li Z, Xuehong Gu (2021) Suresh K; Bhatia, the induced orientation effect of linear gases during transport in a NaA zeolite membrane modified by alkali lignin. J Membr Sci. https://doi.org/10.1016/j.memsci.2020.118971

Huang AS, Liu QA, Wang NY, Tong X, Huang BX, Wang M, Caro J (2013) Covalent synthesis of dense zeolite LTA membranes on various 3-chloropropyltrimethoxysilane functionalized supports. J Membr Sci 437:57-64 
Kazemimoghadam M, Mohammadi T (2006) Preparation of NaA zeolite membranes for separation of water/UDMH mixtures. Sep Purif Technol 47:173-178

Lai ZP., G Bonilla, I Diaz, Nery JG., K Sujaoti, Amat MA., Kokkoli E. Terasaki O.,Thompson RW, M Tsapatsis, Vlachos DG,Microstructural Optimization of a Zeolite Membrane for Organic Vapor Separation. Sci 300: 456-460

Li H, Wang J, Xu J, Meng X, Xu B, Yang J, Li S, Lu J, Zhang Y, He $X$ (2013) Synthesis of zeolite NaA membranes with high performance and high reproducibility on coarse macroporous supports. J Membr Sci 444:513-522

Li L, Chen M, Dong Y, Dong X, Jing L (2016) A low-cost aluminamullite composite hollow fiber ceramic membranefabricated via phase-inversion and sintering method. J Eur Ceram Soc 36(8):2057-2066

Liang Y, Zeng C, Wang C, Zhang L, In situ impregnation-gelationhydrothermal crystallization synthesis of hollow fiber zeolite $\mathrm{NaA}$ membrane.Microporous and Mesoporous Materials, 2017, 244:278-283.

Liang D, Huang J, Zhang H, Hongming Fu, Zhang Y, Chen H (2021) Influencing factors on the performance of tubular ceramic membrane supports prepared by extrusion. Ceram Int 47:10464-10477

Louisa Tak Yin Au, Chau JLH (2001) Carlos Tellez Ariso, King Lun Yeung, Preparation of supported Sil-1, TS-1 and VS-1 membranes: Effects of Ti and V metal ions on the membrane synthesis and permeation properties. J Membr Sci 183:269-291

Lukasiewicz SJ, Reed JS (1988) Specific permeability of porous compacts as described by a capillary model. J Am Ceram Soc 72:1008-1014
Mohamed G, Ismail MU, Hiroshi A, Akiba T (1990) mullite whiskers from precursor gel powders. J Am Ceram Soc 73:2736-2739

Morigami K, Abe K, Okamoto T (2001) first large-scale pervaporation plant using tubular-type module with zeolite NaA membrane. Sep Purif Technol 25:251-260

Park HB, Kamcev J, Robeson LM, Elimelech M (2017) Freeman, Benny D, Maximizing the right stuff: The trade-off between membrane permeability and selectivity. Science. https://doi.org/ 10.1126/science.aab0530

Reed JS (1993) Liquid permeability of packed particles: why perpetuate the Carmen-Kozeny model? J Am Ceram Soc 76:547-548

Shao J, Zhan ZY, Li JG, Wang ZB, Li K, Yan YS (2014) zeolite NaA membrane supported on alumina hollow fibers: effect of support resistances on pervaporation performance. J Membr Sci 451:10-17

Wang B, Zheng Y, Zhang J, Zhang W, Zhang F, Xing W, Zhou R (2019) Separation of light gas mixtures using zeolite SSZ-13 membranes. Microporous Mesoporous Mater 275:191-199

Zhu W, Liu Y, Guan K, Peng C, Jianqing Wu (2021) Design and optimization of ceramic membrane structure: from the perspective of flux matching between support and membrane. Ceram Int 47:12357-12365

Publisher's Note Springer Nature remains neutral with regard to jurisdictional claims in published maps and institutional affiliations. 